\title{
How COVID-19 is changing the world: A statistical perspective from the Committee for the Coordination of Statistical activities
}

\author{
Haishan $\mathrm{Fu}^{\mathrm{a}, *}$, Mark Hereward ${ }^{\mathrm{b}}$, Steve MacFeely ${ }^{\mathrm{c}}$, Angela $\mathrm{Me}^{\mathrm{d}}$ and John Wilmoth ${ }^{\mathrm{e}}$ \\ ${ }^{a}$ World Bank, Washington DC, USA \\ ${ }^{\mathrm{b}}$ United Nations Children's Fund, New York, USA \\ ${ }^{\mathrm{c}}$ United Nations Conference on Trade and Development, Geneva, Switzerland \\ ${ }^{\mathrm{d}}$ United Nations Office for Drugs and Crime, Vienna, Austria \\ ${ }^{\mathrm{e}}$ United Nations Department of Economic and Social Affairs, New York, USA
}

\section{Introduction}

COVID-19 has impacted every state, every community and everyone's life. It has altered macro dynamics, from national economy and public health to international trade, transportation, and security. It has also suddenly changed the microcosm of our families, in terms of schooling, employment, income, and leisure time. As in other crisis, the most vulnerable populations, children, women, the poorest and most marginalized communities, are the ones most affected.

The COVID-19 pandemic has transformed the world in such an unprecedented and rapid way that organizations at all levels -sub-national, national, regional, international - are now confronted with circumstances never experienced before. The virus and containment measures implemented by governments are having dramatic and profound impacts on national priorities and development plans as national and global priorities are suddenly changing. Given the grave impacts of the coronavirus pandemic on our interconnected world, decisions made today will have consequences that will last far into the future, affecting people in every region and community [1]. The situation has exacerbated the challenge of policy making as many decisions have no precedents to build upon. The body of data, statistics

\footnotetext{
*Corresponding author: Haishan Fu, World Bank, Washington DC,
} USA.E-mail: hfu1@worldbank.org. and knowledge that underpinned societies before the pandemic has suddenly become obsolete and more than ever before governments need timely, impartial, and policy-relevant information that can help address the crisis and 'build back better'. National and international official statistics play a critical role in filling this gap and providing the evidence to help guide governments towards a sustainable recovery.

Official statistics have not been immune from COVID-19 disruptions. Data collection activities that relied on field operations have been interrupted, some of the support provided by the international community to national statistical systems has become more challenging to deliver, and the economic crisis risks reducing public funding to national statistics. Despite these challenges, national and international statistical systems have stepped-up to address the urgent need for data that quantify the impact of the pandemic. The Group of Chief Statisticians in regional, supra-national and international organizations - the Committee for the Coordination of Statistical Activities (CCSA) - acted quickly, in the early stages of the pandemic, to support national statistical systems. The CCSA offered the international community a consolidated statistical overview of the impact of the pandemic on the economic, social, and environmental development [2,3]. Benefitting from the wide spectrum of topics covered by the members of the Committee and their long-standing experience in compiling and disseminating impartial data and statistics, two volumes of the report How COVID-19 is changing 
the world: a statistical perspective have been produced to date to describe the impact of the pandemic. 36 organizations have contributed to these publications in the spirit of promoting facts-based planning and policy making. Separately, but in consultation with the CCSA, the World Bank and the United Nations Statistics Division worked hard to understand and minimise the disruption of statistical activities at national level, not least compiling a global COVID-19 survey of National Statistical Offices [4].

These efforts supported the call made by Secretary General of the United Nations, Antonio Guterres to examine the facts based on impartial statistics: 'With common cause for common sense and facts, we can defeat COVID-19 ... and build a healthier, more equitable, just and resilient world'.

The quantitative knowledge presented in the two volumes covers different aspects of public and private life from economic and environmental fluctuations to changes that affect individuals in terms of income, education, employment and violence and changes affecting public services, such as, civil aviation and postal services. The report also puts a spotlight on the effects for some sub-population groups like women and children as well as geographical regions. The volumes also describe the challenges faced by national statistical systems during the pandemic.

\section{Who are the Committee for the Coordination of Statistical Activities?}

The Committee for the Coordination of Statistical Activities (CCSA) as currently configured was established in September 2002. ${ }^{1}$ It is comprised of 45 international and supranational organizations, ${ }^{2}$ whose mandates include the provision of international official statistics in the context of the Principles Governing International Statistical Activities [5] and which have permanently embedded statistical services in their organization and regular contacts with countries.

The formal mandate of the CCSA, as set out in their most recent (2017) Mission Statement. ${ }^{3}$ states the CCSA should:

\footnotetext{
${ }^{1}$ The CCSA was superseded by the ACC or Administrative Committee on Coordination Sub-Committee on Statistical Activities which sat from 1967 until it was disbanded in 2001 and replaced by the CCSA.

${ }^{2}$ Membership of the CCSA can be found at: https://unstats.un.org/ unsd/ccsa/members.cshtml.

${ }^{3} 2017$ Mission Statement https://unstats.un.org/unsd/ccsa/docum ents/TOR\%20final.pdf.
}

1. promote interagency coordination and cooperation on statistical programmes and consistency in statistical practices and development.

2. [Act] as a forum to foster good practices in statistical activities of international and supra-national organisations, in accordance with the Principles Governing International Statistical Activities, and within the constraints of their own governance arrangements and resource envelopes.

3. contribute actively to the development of a coordinated global statistical system producing and disseminating high-quality statistics, e.g. by facilitating the development and well functioning of regional and national statistical systems.

The main activities of the CCSA are to ensure the efficient functioning of the international statistical system; develop common standards, platforms and methodologies; provide inter-institutional support; outreach; and advocacy for high quality official statistics.

As member states tend to deal with different parts of the international system directly, they may not always be fully aware of the important work being undertaken by the CCSA. For this reason, the CCSA reports on their activities to the United Nations Statistical Commission every year. ${ }^{4}$ Those familiar with the international statistical system appreciate and will acknowledge how well the system functions. Since their establishment in 2002, the CCSA has undertaken some important work a short precis is outlined here.

Of fundamental importance, the CCSA endorsed and committed to the implementation of the Principles Governing International Statistical Activities in 2005 (and reaffirmed in 2014 following the adoption by the UN General Assembly of the United Nations Fundamental Principles of Official Statistics in 2014 [6]). The CCSA has developed recommendations and best practice case studies on topics, such as, the dissemination of microdata [7] and the use of unofficial data sources to compile international statistics $[8,9]$. The committee also maintains a Global Inventory of Statistical Standards ${ }^{5}$ so that readers can see at a glance which standards, classifications, definitions etc. are being applied by which agencies.

The CCSA also organises and runs sessions at international conferences, coordinates technical issues, such as, the use of population estimates in the calcu-

\footnotetext{
${ }^{4}$ Annual reports to UN Stat Com are available to read at: https:// unstats.un.org/unsd/ccsa/committee-reports.cshtml (in all 6 official UN languages).

${ }^{5}$ https://unstats.un.org/unsd/iiss/MainPage.ashx.
} 
lation of per capita indicators, undertaking statistical peer reviews and promoting Open Data standards across the international statistical system. More recently considerable effort has been invested in building linkages between the statistical and geo-spatial communities and coordinating data flows for the global reporting of the SDG indicators.

\section{Joining forces to assess the cascading impact of COVID-19}

At the close of the $51^{\text {st }}$ UN Statistical Commission on March $6^{\text {th }} 2020$, it was clear that COVID-19 was rapidly escalating from a regional to a global crisis. There were already more than 98,000 confirmed cases spread across 93 countries or territories. The WHO had already upgraded their global risk assessment to 'very high' on March $1^{\text {st }}$. Within a week of the Statistical Commission, on March $11^{\text {th }}$, the WHO declared COVID-19 a global pandemic [10].

In response to these developments, the CCSA Bureau (the co-chairs, vice-chairs and secretariat) began discussing if and how the CCSA should respond to the COVID-19 crisis. The main question being asked was could the international statistical community in general, and the CCSA specifically, make a positive contribution and do something useful? Following some robust brain storming, it was agreed an inter-agency statistics report on how COVID-19 was affecting the world - How COVID-19 is changing the world: a statistical perspective - would be useful. Given the multi-disciplinary make-up of the CCSA, such a report would speak to broad range of issues, making it useful to the widest range of users.

It was agreed a simple approach should be adopted, so that the report could be published quickly to meet the demand for information to understand the cascading consequences of COVID-19. Consequently, a very simple, standardized template was designed and implemented. Each international organization would complete the template and submit to the editor. At the outset one or two members expressed concern that the CCSA was not mandated to publish a statistical report. From a strict legalistic perspective this was probably true, but from a more holistic interpretation that captured the spirit of the CCSA mandate, rather than the strict letter of the law, a strong counter argument was made. In fact, as a joint report would encourage interagency coordination and cooperation, was in keeping with the Principles Governing International Statistical Activities and would not contravene any individual governance mechanisms (principle 2), and as it would promote the dissemination of high-quality statistics, the view was taken that on balance, a joint statistical report was in keeping with the mandate. More importantly, at a time of global crisis, the CCSA could and should be seen to make a positive contribution, by combatting mis-information and disseminating robust, quality statistical information. The CCSA voted with their feet, within 24 hours of the call being issued, 36 international organisations had volunteered to contribute a chapter.

As this was the first inter-agency CCSA report, a number of licensing and copyright issues had to be addressed. International organisations use a variety of different copyright and licensing agreements and disclaimers. For example, as organisations disseminate their work under a variety of license agreements, the compromise was to license the CCSA publication under Creative Commons Attribution 3.0 IGO. The fact that the CCSA is not a legal entity per se, also threw up some interesting legal discussion as to how the report should be correctly copyrighted. In the end, the report was copyrighted to the CCSA with some rights reserved. Equally, the final disclaimer was a hybrid of several texts sampled from international organisations.

\section{Initial Assessments (Volume 1, May 2020)}

The first volume of the report How COVID-19 is changing the world: a statistical perspective was published on May $13^{\text {th }}$, less than 2 months after the initial discussions had been held by the CCSA Bureau. All of the 36 international organisations that had undertaken to contribute chapters did so, and on time and using the agreed template. The report was divided into five sections: COVID-19; Economic Impact; Social Impact; Regional Impact; and Statistical Impact.

As the introduction to the report noted, it presented only a glimpse or snapshot of the latest information available on how COVID-19 was affecting the world. A dilemma for many data rich organisations was which topic to present; there were so many possible angles and stories. This report would show only the tip of the iceberg. By May $13^{\text {th }}$ the number of confirmed cases had risen to almost 4.2 million spread across 212 countries and territories with the number of reported deaths exceeding 287,000 [11]. If nothing else, the report presented in stark quantitative terms, what an unprecedented crisis COVID-19 had wrought. A whole set of new statistical records were presented in the report; 
trends and levels that would have been unimaginable only 6 months beforehand.

On the economic side, for example, the International Civil Aviation Organization (ICAO) reported that the aviation industry was facing its deepest-ever crisis with $90 \%$ of the global fleet grounded. Unsurprisingly then, the United Nations World Tourism Organisation (UNWTO) projecting a range of scenarios forecasted that tourism arrivals would fall by between $58 \%$ and $78 \%$ in 2020 - far in excess of the downturns experienced as a result of SARS or the 2009 Global Financial Crisis.

Meanwhile, the United Nations Conference on Trade and Development (UNCTAD) noted that global commodity prices had recorded their largest fall on record, dropping a massive $20.4 \%$ in the month to March 2020. Their nowcast for merchandise trade was equally gloomy, predicting a precipitous decline of $27 \%$ for the second quarter of 2020 compared with the same quarter last year.

Growth in global manufacturing, which had already been decelerating in 2019 owing to global trade tensions, were expected to further decline in 2020 due to economic disruptions triggered by COVID-19. The global Industrial Production Index compiled by the United Nations Industrial Development Organization (UNIDO) fell by more than 10 percent between December 2019 and February 2020 (the latest data available at the time the chapter was written). In China, where COVID-19 had emerged first, the decline already exceeded 25 percent; an ominous signal of what might follow elsewhere around the globe.

On the social side, owing to the combined effects of lockdowns, travel restrictions, social distancing policies, and workplace and school closures, significant losses of employment were anticipated. The International Labour Organization (ILO) nowcast that global hours worked were expected to fall by 10.5 per cent in the second quarter of 2020; the equivalent of 305 million full-time workers working a 48-hour work week. They noted that already, the loss in hours worked was worse than that of the 2008-2009 financial crisis.

UNESCO reported that the education of 1.6 billion learners was disrupted, with 9 out of every 10 students in the world affected by school and university closures UNICEF noted that children had other challenges to face at the same time, not least, worsening risks of impoverishment, and lack of access to life-saving vaccinations and increased risk of violence. Meanwhile, efforts to eliminate extreme poverty were being reversed, with the World Bank predicting that global poverty would increase for the first time since the 1998 Asian Financial Crisis. Their nowcasts estimated that between 40 to 60 million people (depending on the scenario) would be pushed into extreme poverty during 2020, that is, living on less than $\$ 1.90$ a day, as a result of the coronavirus pandemic. 6

The first volume also provided a glimpse into the challenges facing national statistical offices in the early stages of the pandemic. At a time when statistics were most needed, many statistical systems were struggling to maintain the production of many basic statistics, highlighting once again the need to invest in data and statistics, and the importance of having modern national statistical systems and data infrastructure.

Reaction to the report was overwhelmingly positive. From within the UN system, the Chief Executives Board for Coordination (CEB) 'welcomed How Covid-19 is changing the world: a statistical perspective, published by the Committee for the Coordination of Statistical Activities (CCSA), as a strong example of what the international statistical community can achieve when confronted with a dire global challenge' [12]. Several individual Secretary Generals and Chief Executives also issued public statements welcoming the report and noting its important contribution. This political support was important, as obviously, production of the report had diverted precious resources from other activities, especially for the organisations editing the report. There was of course widespread interest abroad also, with good media interest and traffic on social media platforms. Blogs were posted by the World Bank [13], World Economic Forum [1] and on the SJIAOS Discussion Platform dedicated to 'Official Statistics in the context of the COVID-19 crisis'?

\section{The first update (Volume 2, August 2020)}

The first volume was in many ways an experiment could the CCSA bring together its voluminous and broad expertise to give a compact summary of statistical insights in a timely way? The answer was not only "yes", but appreciation from many quarters - not least

\footnotetext{
${ }^{6}$ In the second volume [3], the World Bank updated this to between 71 and 100 million as more data became available. Many other agencies updated their forecasts also. For example, the ILO revised their global loss of working hours from $10.5 \%$ to $14 \%$. These revisions only served to highlight further the need for regular updates as the impact of COVID-19 deepened (see Section 5).

${ }^{7}$ See: https://officialstatistics.com/news-blog/crises-politics-andstatistics?page $=1$.
} 


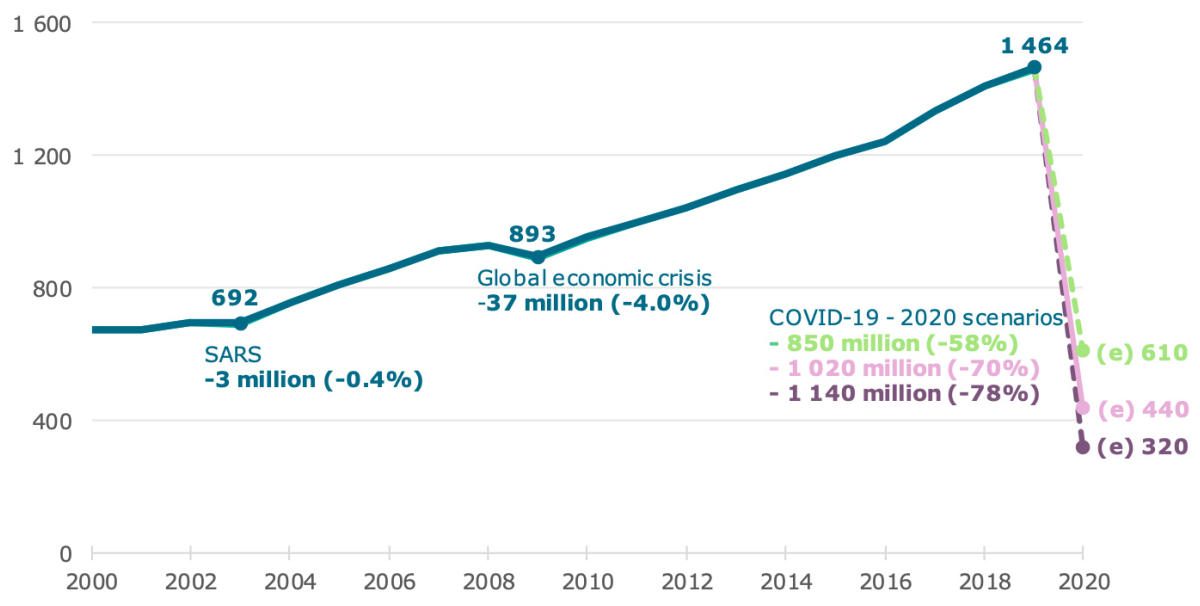

Fig. 1. Forecast International Tourism Arrivals (millions). Source: UNWTO [2].

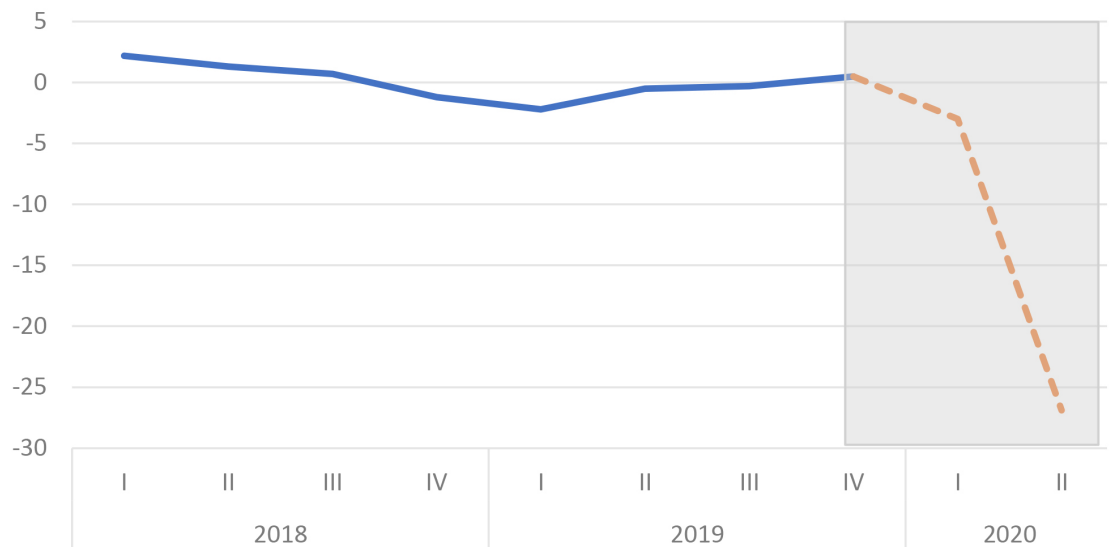

Fig. 2. Global Merchandise Trade (value) Quarter on Quarter growth rate (seasonally adjusted). Source: UNCTAD [2].

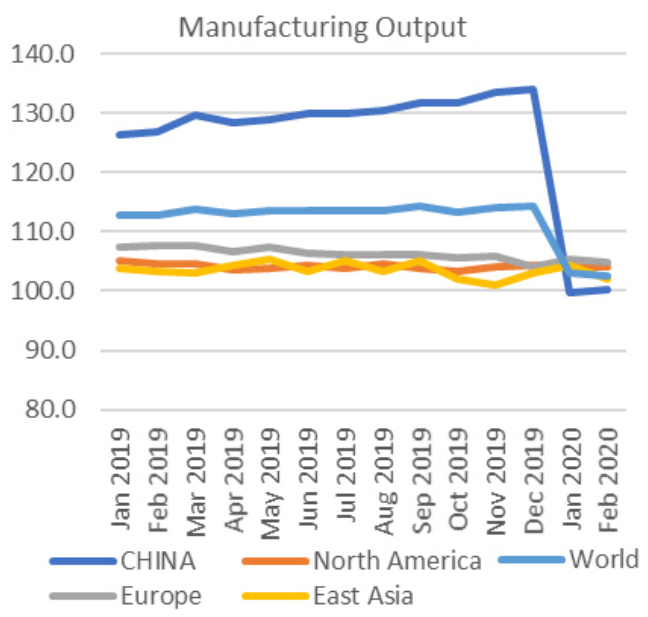

Fig. 3. Manufacturing Output Index, Jan 2019 - Feb 2020. Source: UNIDO [2]. the Secretary-General of the United Nations - led to a decision to have a subsequent volume, and to aim for a quarterly publication at least through the height of the pandemic. Furthermore, the deepening consequences of the pandemic demanded an update of the initial assessments presented in May.

Slightly fewer organizations (31, down from 36) were able to contribute so soon after the first volume, but there was still an impressively broad range of topics covered in an incisive way. The second volume had one article covering the different dynamics of the epidemic in various countries, ten entries on economic issues, six on social impact, six more which look at issues by region, and eight on the impact on statistics themselves. This balance shows a greater degree of attention to statistical impact, and lighter set of contributions on social impact - both are evidence of statistical challenges.

The second volume built on the first estimates and impacts presented with more thorough-going and far- 


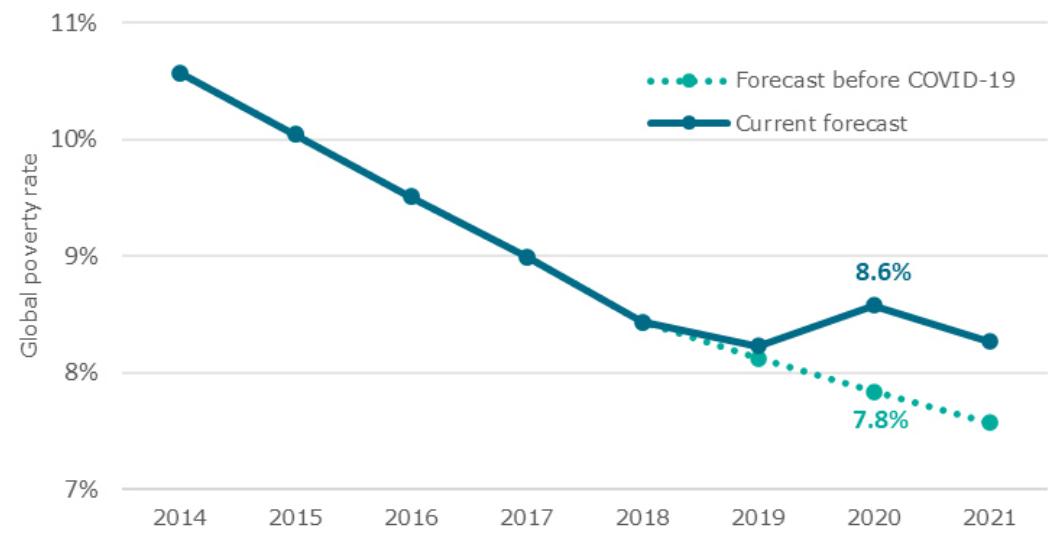

Fig. 4. The Impact of COVID-19 on Global Poverty. Source: World Bank [2].

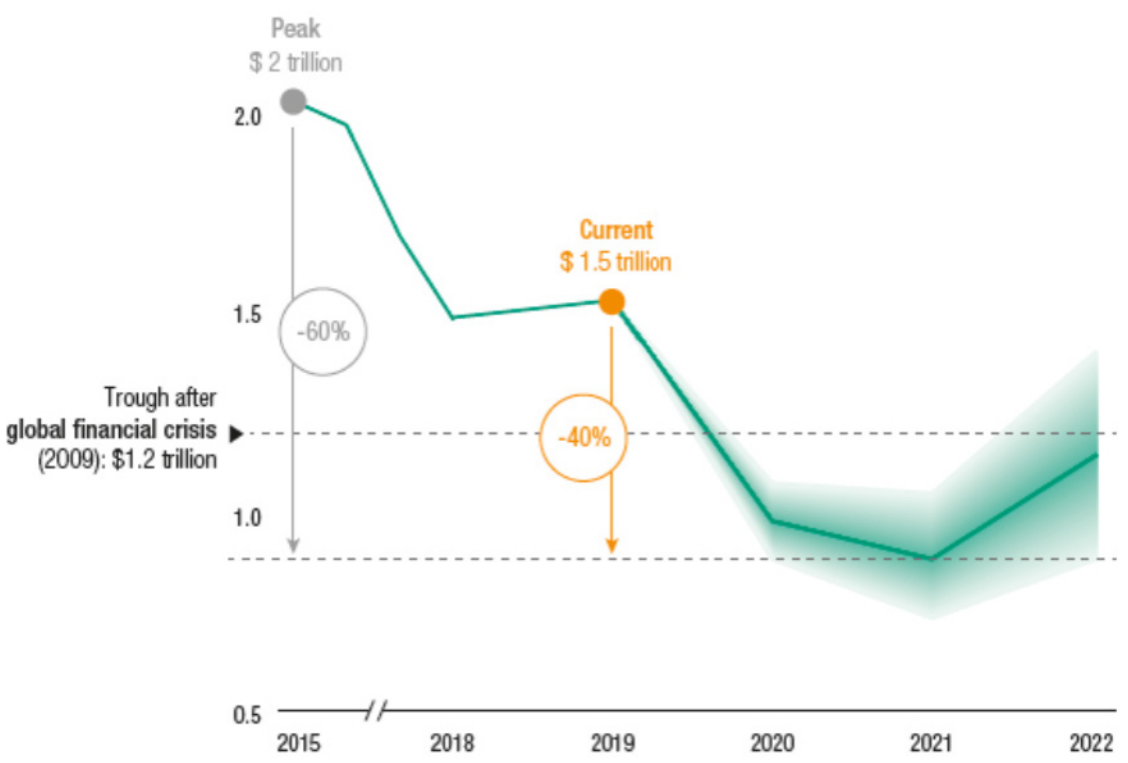

Fig. 5. FDI inflows, 2015-2019 and 2020-2022 (USD, Trillions). Source: UNCTAD [3].

reaching analytical work. The impacts of the pandemic (and its control measures) on a whole range of longerterm outcomes was starting to show, and 'what-if' scenarios were being replaced by scenarios based on new data. Yet data constraints continue to hamper and be a statistical concern as we move forward. Traditional data sources that involve reporting (administrative data systems) or face-to-face data collection (household and other surveys) have been interrupted - some of them for the long term. While some household surveys are restarting, for example, in many countries the risk of disease transmission is deemed greater than the risk of lack of data.

The statistical community has mobilized to use different forms of data collection - telephone surveys in place of face-to-face interviews, for example, and moving faster to tap into news and social media sources using Big Data analytical techniques, but there remain severe limitations and tendencies to bias in all of these methods.

So, indeed, the demand for data has never been so great or important - at the same time as the supply of data never having been so troubled. The whole statistical community faces this conundrum and is working to find 'fit for purpose' solutions to guide action and thinking, whilst covering them in caveats.

\subsection{A grimmer picture}

The statistics presented in the second report provide an even grimmer picture than what was presented in the 


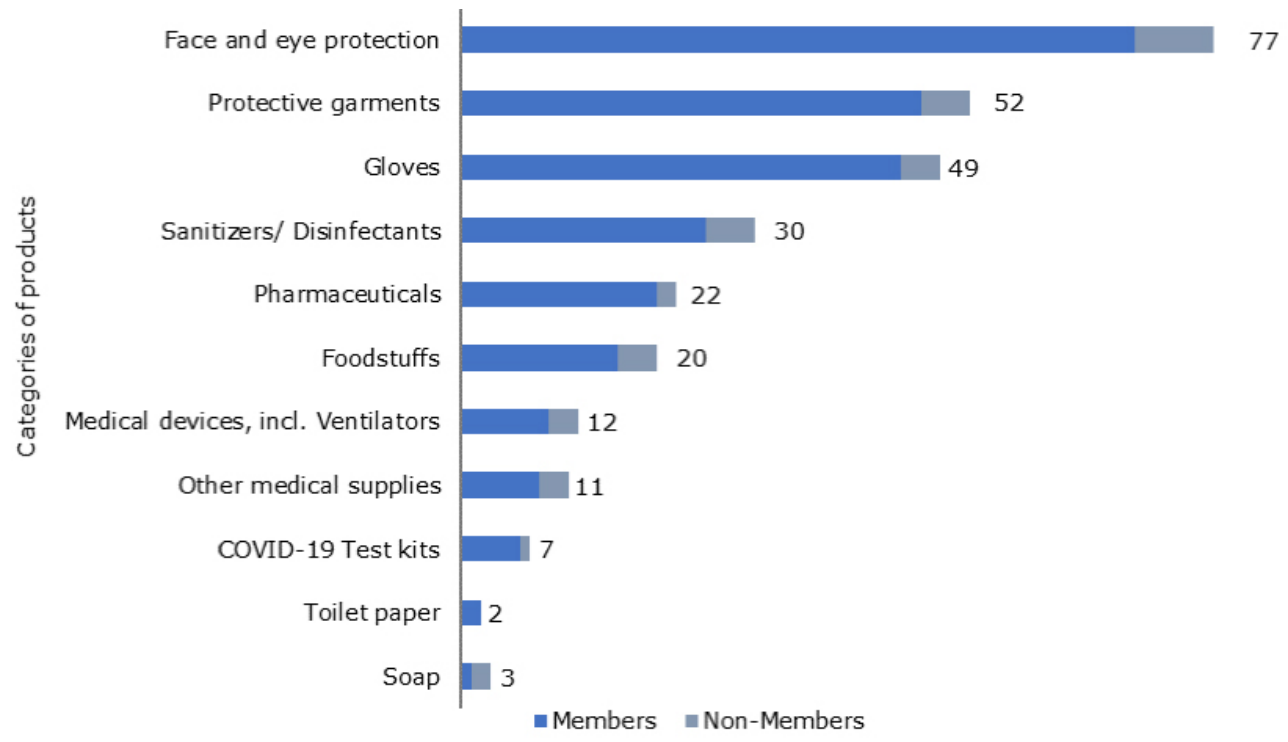

Fig. 6. Number of export prohibitions and restrictions introduced to combat the COVID-19 pandemic, by type of product and WTO membership status. Source: World Trade Organization [3].

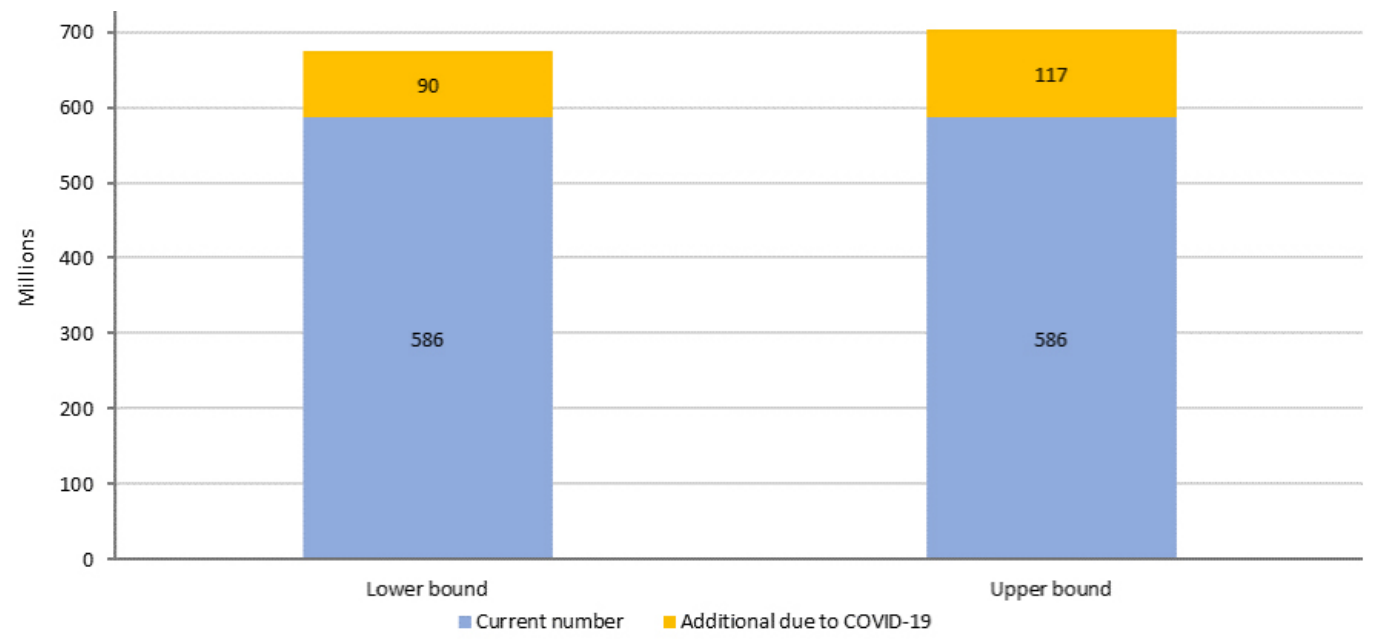

Fig. 7. Number of children in monetary poor households. (Estimates based on national poverty lines). Source: UNICEF and Save the Children [3].

first edition for most parts of the world, confirming the unprecedented magnitude of the havoc being wrecked by the pandemic in our economic and social fabric. For instance, the United Nations Industrial Development Organization (UNIDO) estimated that global manufacturing, which already exhibited a decelerating trend in 2019, fell by $20 \%$ in April 2020 compared to the same period of the previous year. Whereas data for China are indicating a fast recovery, the manufacturing slump in other countries is deepening. At the same time, the UNCTAD forecasted a dramatic drop in foreign direct investment (FDI) in 2020 and 2021. More specifically,
UNCTAD projected that the global FDI flows to fall by as much as 40 percent in 2020, compared with their 2019 value of $\$ 1.5$ trillion. FDI is forecasted to decrease by a further 5 to 10 percent in 2021 .

The COVID-19 pandemic triggered an enormous shock in the global demand for medical products, which depend largely on international trade and global supply chains. According to the World Trade Organization, as of 18 May 2020, 85 countries and customs territories had introduced export prohibitions and restrictions to mitigate critical shortages at the national level.

The updates by the ILO and the World Bank exem- 


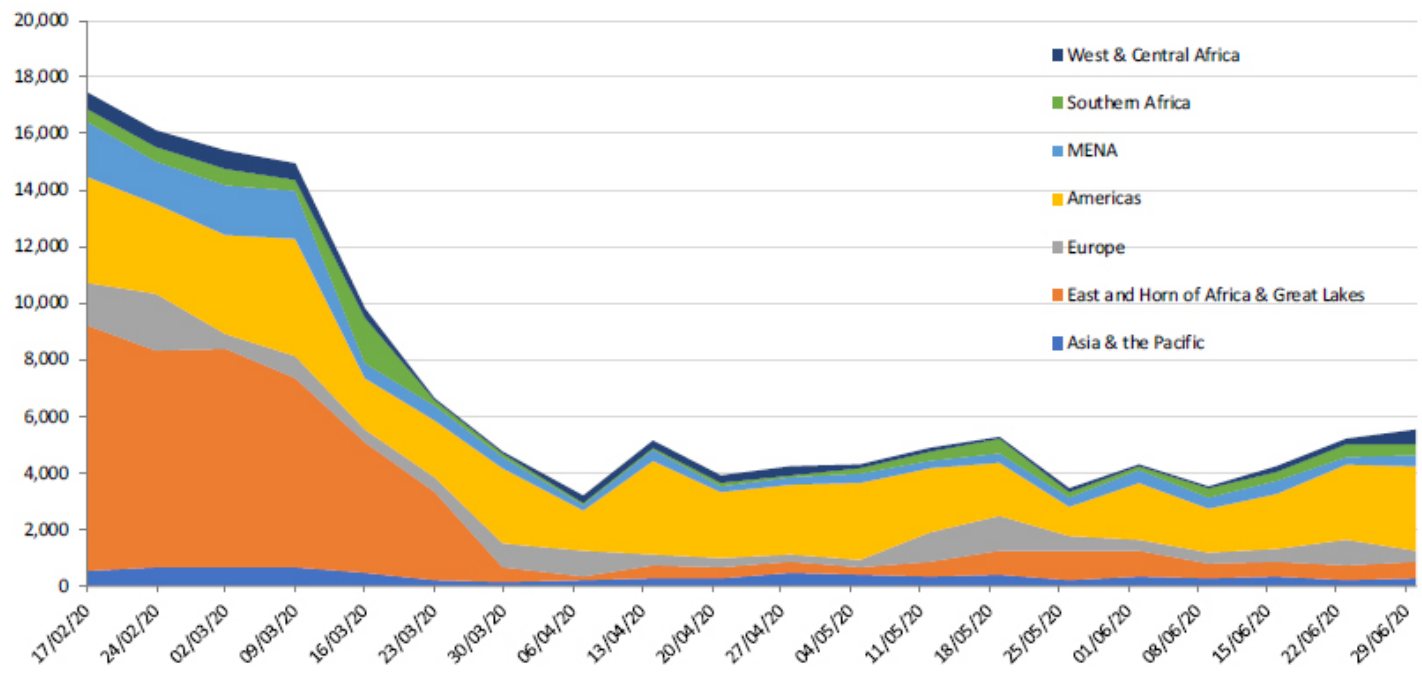

Fig. 8. UNHCR weekly refugee registration. Source: UNHCR [3].

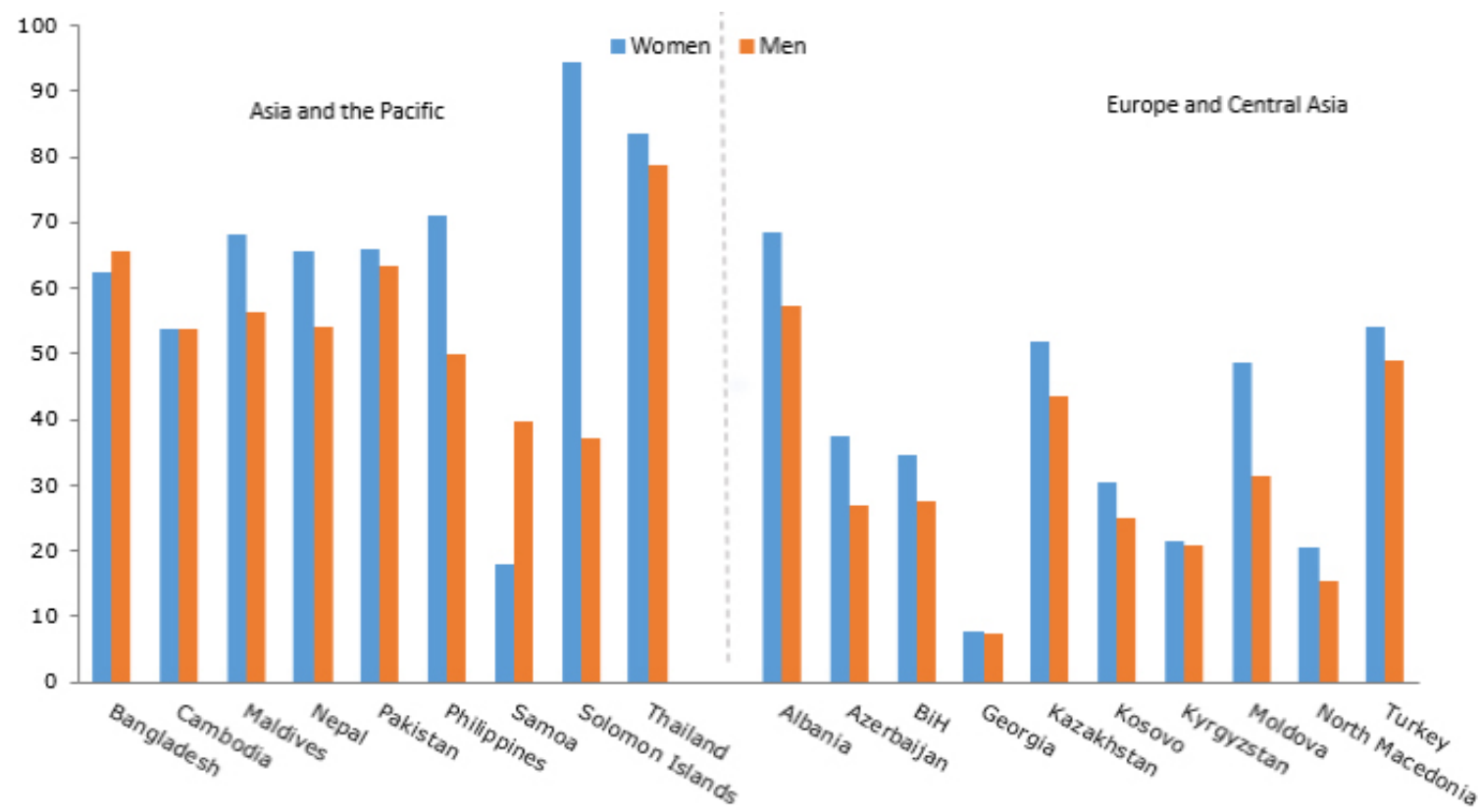

Fig. 9. Proportion of population who reported that their psychological/mental/emotional health was affected since the spread of COVID-19 in selected countries, by sex (percentage). Source: UN Women [3].

plify the grimmer-than-before situation. According to ILO's update, working hours dropped by 5.4 per cent in the first quarter of 2020 and 14 per cent in the second quarter, relative to the last quarter of 2019, which were much larger than initially estimated. Women workers are especially bearing the brunt of the crisis, with female employment at greater risk of disruption and an increased burden of unpaid work on women. The World Bank now estimates that the pandemic is pushing about
71 to 100 million people into extreme poverty (living on less than $\$ 1.90$ a day).

On the other hand, UNICEF and Save the Children estimated that fall in economic growth, combined with and historical trends in changes in income distribution (in particular during years of crises) mean that between 90 and 117 million additional children in monetary poor households in developing countries according to nationally defined poverty lines. 
The statistics also highlight the disproportionate impact of the pandemic on some populations. For instance, while refugee registration is an essential protection activity conducted by the field staff of the United Nations High Commissioner for Refugees (UNHCR), it had dropped significantly in the period between midFebruary and mid-April 2020, remaining quite stable since then.

\subsection{Vulnerabilities}

UN Women, on the other hand, conducted a set of rapid gender assessment surveys (RGAs) in partnership with the public and private sector, using internet, landline and mobile phone-based data collection techniques to understand the gendered consequences of COVID19. According to these surveys, women did three times more unpaid domestic and care work than men before the pandemic. While the crisis has led to increases in the workload for both women and men, women shouldered the extra burden. At the same time, high rates of mental and emotional distress were reported, with women reporting higher rates than men. Increases in unpaid care and domestic work, job and income loss, and increased gender-based violence may be some of the leading reasons for this increase.

\section{Conclusion}

The COVID-19 pandemic has shown the critical importance of internationally comparable impartial statistics. Simply looking at statistics on COVID-19 deaths and cases, it is clear that understanding and addressing the pandemic require data that can cross borders and can be trusted by all. With the challenges to ensure continuity in the statistical production process, COVID-19 has also brought to official statistics the opportunity to modernize. The sudden need for real-time statistics and data that can quickly respond to fast changing policy needs represent a wake-up call for national and international statistical systems. A call that accelerates the process of modernization launched by some national statistical offices, the UN Statistical Commission, and the UN chief statisticians [14]. Such innovation requires data collection systems that can remain operational during times of crisis and can quickly monitor fast moving phenomena. For some national and international statistical offices, this may require experimenting with new methodologies or techniques (such as nowcasting), acquiring new technologies (for example to operate re- motely) and embracing new forms of data collection (such as big data or citizen-driven data collection).

The collaborative effort involved in putting together this new statistical report - bringing together 36 international organizations to provide high-quality statistics on COVID-19 and its impacts is as an example of the kind of collaboration that will be critically needed going forward. But we should not forget, the reason that the CCSA were able to share these snapshots into the impacts of COVID-19 is because of the existing investments that have been made by the national and international communities into the field of statistics. Unfortunately, the pandemic is posing a significant challenge to this vital area of knowledge about our world. Statistical capacity is being squeezed around the globe, particularly in low-income countries that have limited resources to invest into their public goods. So, we remind everyone, who benefits from the CCSA reports, there is no such thing as a free statistic.

\section{References}

[1] MacFeely S, Me A, Fu H. The impacts of COVID-19 around the world, as told by statistics. World Economic Forum Agenda, May 26, 2020. Available at: https://www.weforum. org/agenda/2020/05/statistics-are-key-to-understandingCOVID-19/ [last accessed 19.08.2020].

[2] CCSA (2020a). How Covid-19 is changing the world: a statistical perspective - Volume 1. May 2020. Available at: https:// unstats.un.org/unsd/ccsa/pubs/ [last accessed: 19.08.2020].

[3] CCSA (2020b). How Covid-19 is changing the world: a statistical perspective - Volume 2. August 2020. Available at: https://unstats.un.org/unsd/ccsa/documents/covid19-reportccsa_vol2.pdf [last accessed: 05.10.2020].

[4] United Nations Department of Economic and Social Affairs and the World Bank (2020). Monitoring the state of statistical operations under the COVID-19 Pandemic - Highlights from a global COVID-19 survey of National Statistical Offices. June 2020. Available at: https://unstats.un.org/unsd/COVID19-resp onse/covid19-nso-survey-report.pdf [last accessed 05.10. 2020].

[5] CCSA (2005). Principles Governing International Statistical Activities. Available at: https://unstats.un.org/unsd/ccsa/prin ciples_stat_activities/ [last accessed: 05.10.2020].

[6] United Nations (2014). Fundamental Principles of Official Statistics. Resolution A/RES/68/261 adopted by the Sixtyeighth session of the General Assembly on 29 January 2014. Available at: https://unstats.un.org/unsd/dnss/gp/FP-New-E. pdf [last accessed: 05.10.2020].

[7] CCSA (2014). Microdata dissemination best practices. Available at: https://unstats.un.org/unsd/ccsa/documents/microdata. pdf [last accessed: 19.08.2020].

[8] CCSA (2013). Recommended Practices on the Use of NonOfficial Sources in International Statistics. Available at: https:// unstats.un.org/unsd/ccsa/documents/practices.pdf [last accessed: 19.08.2020]. 
[9] CCSA (2016). Case studies: using non-official sources in international statistics. Special issue paper of the Committee for the Coordination of Statistical Activities (CCSA) Available at: https://unstats.un.org/unsd/ccsa/documents/Epublication.pdf [last accessed: 19.08.2020].

[10] UNCTAD (2020). COVID-19: Measurement issues and assessments. SDG Pulse 2020. In Focus 2020. Available at: https://sdgpulse.unctad.org/covid-19/ [last accessed: 19.08.2020].

[11] World Health Organization (2020). Coronavirus disease (COVID-19) Situation Report - 114. May 13, 2020. Available at: https://www.who.int/docs/default-source/coronaviruse/situ ation-reports/20200513-covid-19-sitrep-114.pdf?sfvrsn=17 ebbbe_4 [last accessed 19.08.2020].
[12] CEB (2020). Note to correspondents on the virtual meeting of the Chief Executives Board. May 14, 2020. Available at: https: //www.un.org/sg/en/content/sg/note-correspondents/2020-05 -14/note-correspondents-the-virtual-meeting-of-the-chiefexecutives-board [last accessed 19.08.2020].

[13] Fu H. How How COVID-19 is changing the world: a statistical perspective from international agencies. World Bank Blogs, May 13, 2020. Available at: https://blogs.worldbank.org/open data/how-covid-19-changing-world-statistical-perspectiveinternational-agencies [last accessed: 19.08.2020].

[14] CEB (2020). System-wide Roadmap for Innovating UN Data and Statistics, Chief Executive Board. May 2020. Available at: https://unstats.un.org/unsd/unsystem/documents/CEBSegment2-Roadmap.pdf [last accessed 3.10.2020]. 